\title{
Behavior of compacted Ca-bentonite subjected to HMC loading: observations and interpretation
}

\author{
Takayuki Motoshima ${ }^{1}$, Sachie Iso $^{1}$ and Tomoyoshi Nishimura ${ }^{2}$ \\ ${ }^{1}$ Civil Engineering Department, Nuclear Facilities Division, Taisei Corporation, Japan \\ ${ }^{2}$ Department of Civil Engineering, Ashikaga University, Japan
}

\begin{abstract}
This study presents result of HMC experimental test and discussions of chemical effort in $\mathrm{Ca}$ bentonite. SWCC test, swelling pressure test and unconfined compression test as hydro-mechanical-chemical (HMC) test were applied to Ca-bentonite-sand mixture. Na-type bentonite has been studied to predict safety and confidence for artificial barrier layer consist of bentonite that many experimental research reports are represented, and can offer technology advanced comprehensive performance due to mathematical simulation models associated to physical parameters on thermal-hydration-mechanical-chemical properties. This study proposed a significant property for calcium bentonite to relate evaluating safety in radioactive waste disposal system, which emphasised much influence of suction and salinity chloride to hydration-mechanical behaviour for Calcium bentonite.
\end{abstract}

\section{Introduction}

In some countries, the safety requirements for geological disposal rest in the following principles: defence-in-depth, demonstrability and the radiation protection principles. Research and development (i.e., R\&D) on safety-relevant thermo-hydro-mechanical-chemical (THMC) issues is significant important to make confidence in the safetydesign assessment. For the high-level radioactive waste geological disposal, multi-barrier concept with geological barrier such host rock and engineered barrier is usually considered (IGD-TP, 2011). The Horonobe Underground Research Laboratory project of the Japan Atomic Energy Agency (JAEA) aims to study the deep geological environment in sedimentary rocks. In the situation of nuclear radioactive waste disposal, the barriers are subjected to thermal-hydraulic-mechanical-chemical (THMC) loadings as resulted from water flow and from heat emission of the waste canisters and from field stress/swelling.

In the laboratory, a large number of studies have also been performed on the thermos-hydro-mechanical (THM) behaviour of difference kinds of bentonite-based materials (Villar. (2005) [1]). Mokni et al., (2014) [2] described THM behaviour of Boom Clay with various the chemical composition of pore-water that some properties such as parameters of compression, hydraulic conductivity and thermal effect were discussed. Xiaodong et al., (2011) [3] mentioned result of chemical-thermal analysis using Wyoming bentonite (MX-80), Chinese bentonite (GMZ) and German Friedland (FIM) that $\mathrm{Ca}^{2}+$ replaced $\mathrm{Na}+$ as adsorbed cation, and $\mathrm{Na} 2 \mathrm{O}$ increase in the hot part in clay by migration of $\mathrm{Na}$ from the colder. In changes of physical properties due to heating at a range from 80 to 90 degrees Celsius a reduction of swelling pressure performed to some clays, and became significant stiffer and more brittle and the increase of hydraulic conductivity was indicated.

Lee et al., (2012) [4] investigated the swelling behaviour of Ca-bentonite that the effect salinity on the swelling pressure was different with $\mathrm{Na}$-bentonite. Such a swelling behaviour of the Ca-bentonite was explained on the ion-exchange of $\mathrm{Ca}^{2}+$. The swelling pressure models, which were proposed using empirical models, double layer models and thermodynamic models. Some papers reported the swelling pressure of $\mathrm{Ca}$-bentonite with sufficient experimental data (Ceneste et al., (1990) [5]) including ion-exchange solutions.

\section{Purpose of this study}

This study presents result of HMC experimental test and discussions of chemical effort in $\mathrm{Ca}$ - bentonite. SWCC test, swelling pressure test and unconfined compression test as hydro-mechanical-chemical (HMC) test were applied to Ca-bentonite-sand mixture. Concentrations of soluble salt were difference, its effect on swelling deformation, swelling pressure and strength were described in basis of experimental data sets. A chemicalhydro oedometer cell and a developed thermal triaxial compression apparatus that allows measurement of swelling pressure due to salt water, and to quantify the apparent cohesion and stiffness in unsaturated-saturated Ca-bentonite. Also, unconfined compressive strength implied the dependence on suction. In addition, coefficient of permeability was measured to a distilled water and a salinity chloride solution under various dry densities.

\footnotetext{
$\overline{2}$ Corresponding author: tomo@ashitech.ac.jp
} 


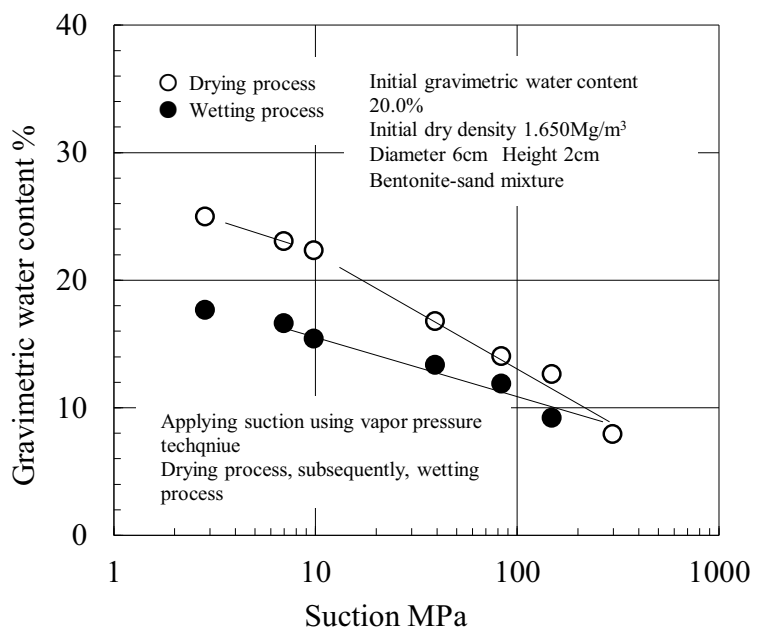

Figure 1. Soil-water characteristic curve under high suction ranges.

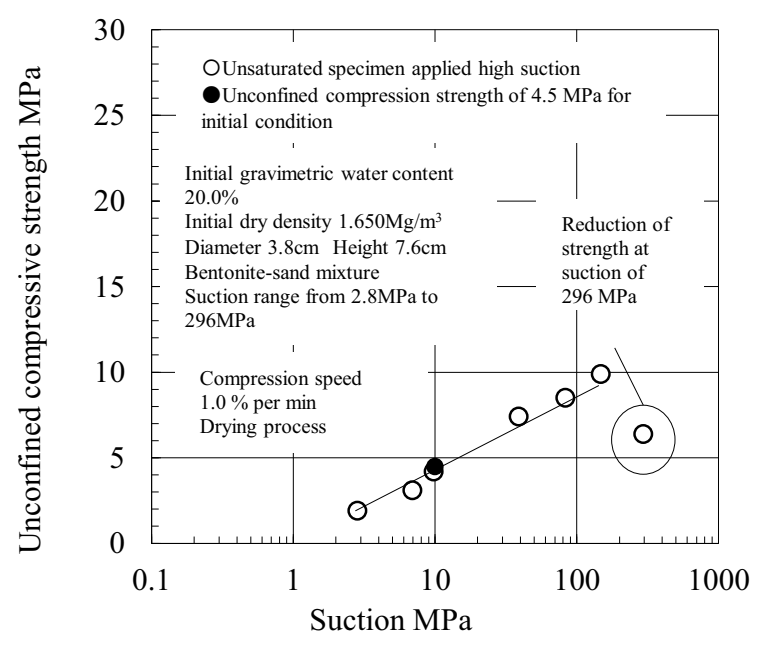

Figure 2. Increment of strength with increasing of suction.

\section{Testing procedure}

\subsection{Soil materials and summary of specimens}

A bentonite used in this study was called as Kunibondo, which was classified as Ca-bentonite (i.e. Calcium type bentonite), and it was used for investigation of stabilization to artificial barrier system composing bentonite. Misawa sand was mixed to the Kunibondo that had on uniform in grain size distribution in grain. The mixture ratio was seven to three, water content reached to $20 \%$ and it is around optimum water content in Proctor's compaction theory.

Specimen was arranged in statically compaction which had a dry density of $1.65 \mathrm{Mg} / \mathrm{m}^{3}$. Sizes of specimen had two different that one was dimeters of $6.0 \mathrm{~cm}$ and a height of $2.0 \mathrm{~cm}$, another one was a diameter of $3.8 \mathrm{~cm}$ and a height of $7.6 \mathrm{~cm}$ so that the specimen mentioned later sizes (i.e. a diameter of $3.8 \mathrm{~cm}$ ) was used in case of unconfined compression test such as mechanical test. A ratio of height to diameter was 2.0 , it was common specification for shear test in soil mechanics.

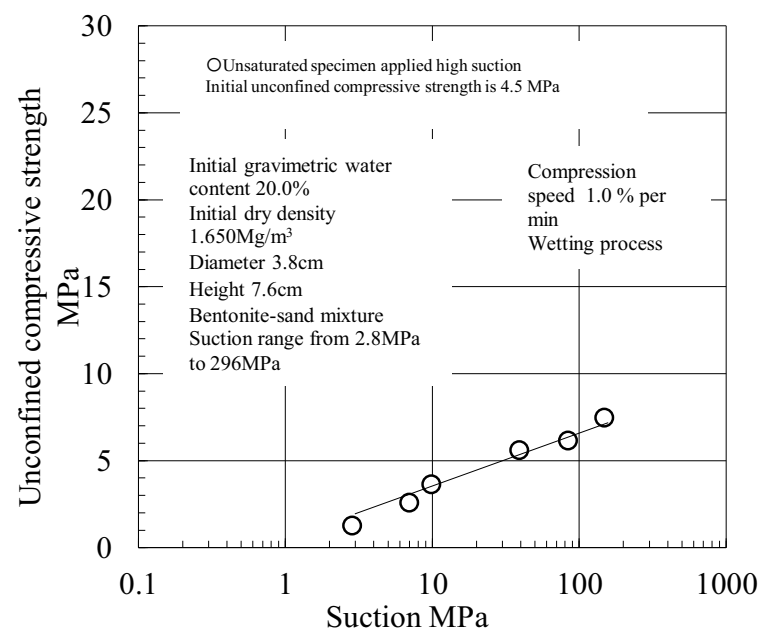

Figure 3. Decreasing of strength due to suction reduction.

The Calcium bentonite described soil-water characteristic curve as shown in Fig. 1, which was a key parameter to predict hydration-mechanical behaviour for expansive soil with much montmorillonite fractions. The SWCC had a range from 2.8 MPa to $296 \mathrm{MPa}$ a limitation in suction that was high suction ranges. Beyond determination of soil moisture on drying process (i.e. suction increment up to $296 \mathrm{MPa}$ ), wetting process due to decrease suction was continued till suction of $2.8 \mathrm{MPa}$. Hysteresis associated to water content between drying process and wetting process was obviously, as well as, many experimental reports realized the influence of increment and decrement of suction on soil moisture. The confirmation that adsorbed water was small value under decreasing of suction, and water content was plotted lower comparison with water contents obtained in drying process.

\subsection{Testing apparatus}

A conventional triaxial apparatus was used for measurement of unconfined compressive strength of compacted bentonite. The apparatus was constructed that double cells were prepared, and put cell was made of steel material and inner cell was made of acrylic material, respectively. The loading cell sensor was placed inside of cell and dial gauge measured the vertical deformation for specimen. The loading sensor had a capacity of 2 tons, and the dial gauge had a capacity of $30 \mathrm{~mm}$. Compression speed is possible to control a range from $0.001 \mathrm{~mm}$ per min to $9.0 \mathrm{~mm}$ per min. A membrane with a thickness of $0.5 \mathrm{~mm}$ covered the whole specimens.

Swelling deformation and swelling pressure are significant parameters that are useful to identify the yield surface associated to suction change, and mathematical simulation models in physical- chemical properties. This testing program used a developed unsaturated oedometer apparatus consisting of outer cell and stiffness steel mold. The steel mold had an inside diameter of $6.0 \mathrm{~cm}$ and a height of $6.5 \mathrm{~cm}$ which made of stainless steel (Material symbol: SUS 316), and other portions such as basement, valve, loading load and plate consist of SUS316 stainless 
steel material. It is possible to prevent corrosion induced by a chloride ion, chloride solutions and a salt water. It is necessary to evaluate vertical way swelling deformation due to absorb using distilled water and chloride ion water, and to determine the swelling pressure at constant volume. The apparatus can apply cell pressure into cell that it therefore corresponds the determination saturated conductivity (i.e. measurement of coefficient of permeability) for saturated calcium bentonite specimen while a volume was maintained, so that a height of specimen was constant. Well, water solutions with various mol concentration had flowed into the specimen.

\subsection{Testing program}

Unconfined compression tests were conducted to determine unconfined compressive strength and stiffness, which were important mechanical values as fundamental parameters for consideration the safety at long terms to artificial barrier system. Evaluating the stress-strain curves with various compression speeds was of a range from $0.01 \% / \mathrm{min}$ to $1.0 \% / \mathrm{min}$. Compression process had remained till the peak strength was obviously observed. Beyond the exhibition of peak strength, much reductions were permitted for compacted high dense bentonite. All specimens for unconfined compression test were applied high suction more than $2.0 \mathrm{MPa}$ that vapor pressure technique contributed to produce high suction accurately. All suctions corresponded to the suctions required in SWCC test as shown in Fig. 1.

Swelling deformation test determined the reduction of dry density according to expansion of vertical way for specimen. Previously, external loading that were $186 \mathrm{kPa}$ and $1500 \mathrm{kPa}$. Subsequently two above vertical stress had not deformed in vertical displacement because of statically compaction stress for preparing initial specimen was over $5 \mathrm{MPa}$ such as yield compression stress in order to produce a dense up to $1.65 \mathrm{Mg} / \mathrm{m}^{3}$. Distilled water was absorbed through porous stone filter installed a basement that changing of absorbed water was measured using a differential pressure transducer in production by VALIDYINE ENGINEERING Co., which put in a double glass burette. Measuring of vertical displacement remained over sixty days. In addition, swelling pressures were observed that solutions with various sodium chloride mol concentration were induced swelling performance, and distilled water compared to these sodium chloride solutions. It is peer to remain initial height during swelling pressure test.

It is possible that natural ground water in rock around barrier stream submerge into compacted bentonite, and cause quality reduction as hydration behaviour. Accuracy prediction of hydration permeable is fundamental key components for safety production that this study concerned the influence of chloride ion solution on saturation conductivity. Decision of coefficient of permeability was conducted that the distilled water and chloride solution were submerged and flow out due to encourage adequate hydraulic gradient. Conductivity was evaluated following Darcy's law with long times, because all the specimens had essentially extremely much low

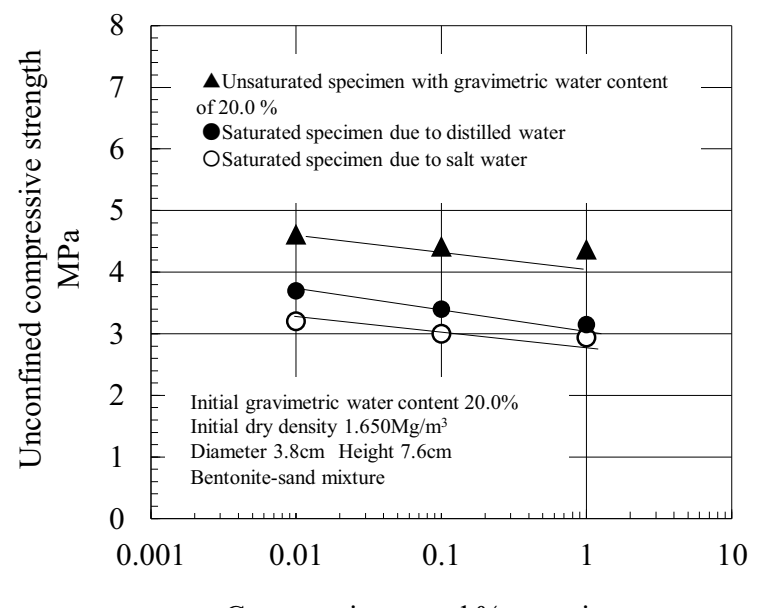

Compression speed \% per min

Figure 4. Strength subjected to hydration and chemical effect considering compression speed.

permeable materials. All salinity for solutions were measured using a salinometer at inflow side and outflow side.

\section{Unconfined compressive strength under high suction ranges}

A bentonite used for construction barrier system has high expansive properties and highly water retention activity that has been studied to prediction of reaction to contact with moisture. Unconfined compressive strength evaluated as apparent cohesion that is possible to take firstly in convention test. The unconfined compressive strength of calcium bentonite increased according to increase suction as shown in Fig. 2, which correspond to decrease gravimetric water content considered in Fig. 1. To decrease soil moisture directly relate to be increment of shear resistance. It is therefore that strength had a linear increasing in logarithmic scale till suction of $148 \mathrm{MPa}$. It could not explain that strength was small comparison with that of suction of $148 \mathrm{MPa}$ when suction was $296 \mathrm{MPa}$. Beyond the drying process, suctions gave back to same suction value on drying process. All specimen at each suction on wetting process had small water content comparison with that of drying process. Measured strengths were placed lower portion with linear relationship as shown in Fig. 3, and was approximately seemed to be parallel with strength line on drying process. The strength subjected to increment and decrement in suction were confirmed that unconfined compressive strength indicated hysteresis between drying process and wetting process, and induced reduction to strength in dying process.

Other hand, this study investigated the influence of compression speed on unconfined compressive strength for calcium bentonite subjected to hydration effort due to absorption using distilled water and chloride solution with salinity of $3.5 \%$. Applied compression speed is a range from $0.01 \%$ per min to $1.0 \%$ per min, which the $1.0 \%$ 


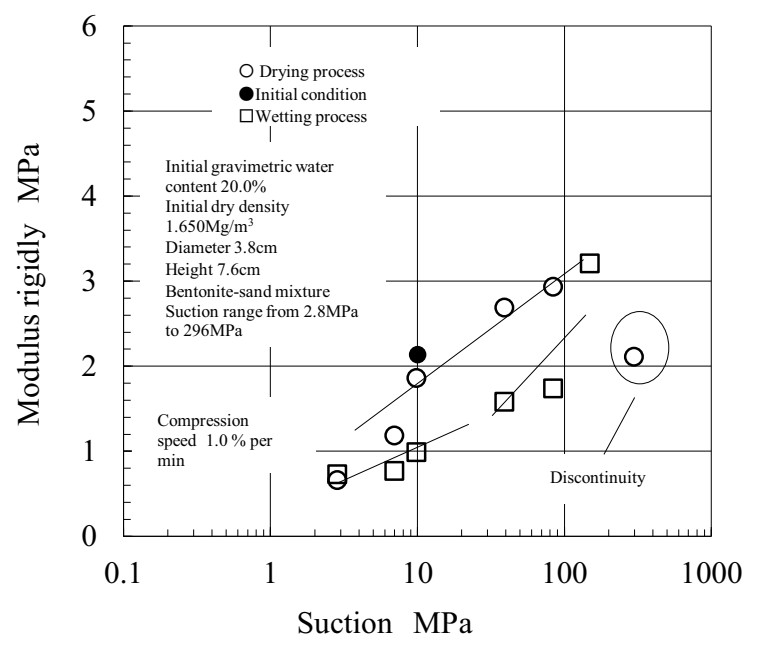

Figure 5. Strength subjected to hydration and chemical effect considering compression speed.

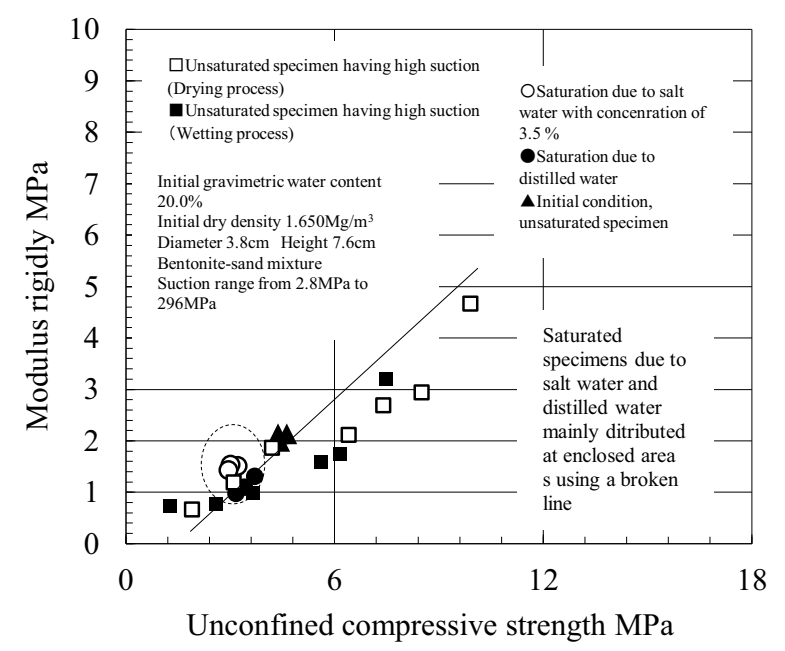

Figure 6. Strength subjected to hydration and chemical effect considering compression speed.

per min was stipulated, was provided as JIS A 1216 geotechnical testing cord. Unsaturated specimens were compared to saturated specimens including distilled water and chloride solution that unconfined compressive strength with compression speed was revealed, the reduction of strength was obviously as shown in Fig. 4. It was found similar results for composite of unsaturated specimens and saturated specimens regardless of salinity, taking into account essentially depending of compression speed to unconfined compressive strength for calcium bentonite.

\section{Modulus rigidly for calcium bentonite}

A modulus rigidly is accepted as fundamental parameters to predict stress-strain behaviour for geotechnical materials, and it has been always required on artificial barrier system design works. Above mentioned, many specimens were used for unconfined compression test that modulus of rigidly was determined from stress-strain curve without lateral confining pressure, and it was

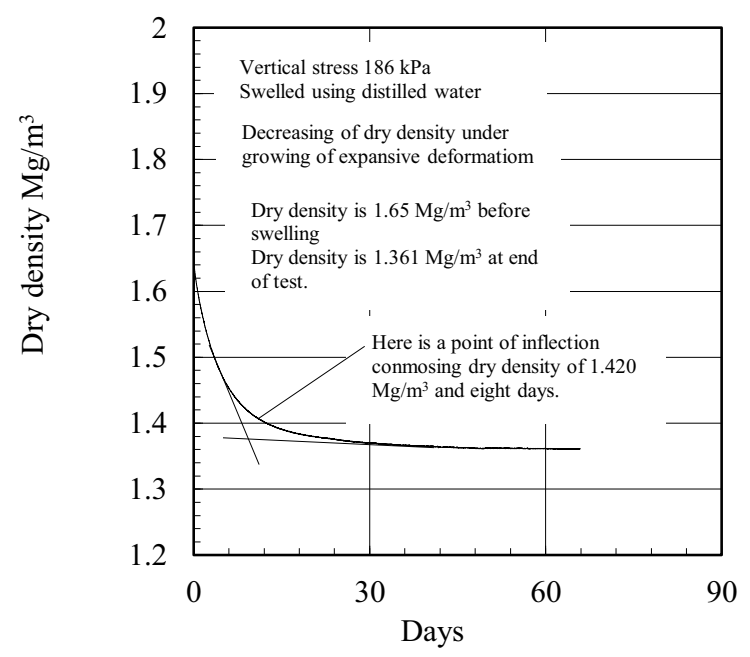

Figure 7. Reduction of dry density in swelling deformation test at vertical stress of $186 \mathrm{kPa}$.

defined as ratio of half of unconfined compressive strength on the axial strain (i.e. corresponding to half of unconfined compressive strength). Calcium bentonite having high suction verified the modulus of rigidly as shown in Fig. 5 that it found modulus of rigidly increased with suction, as well as increment of suction induced increasing of strength mentioned in Figs. 3 and 4. It was therefore accepted to be hysteresis due to repeat of suction application. Summarized relationship between unconfined confined compressive strength and modulus of rigidly was verified in Fig. 6 from all data sets which was a composite of unsaturation and saturation. Prediction of the modulus of rigidly that it is possible to using unconfined compressive strength. The collected many data sets lead to a satisfied straight line.

\section{Swelling properties of calcium bentonite}

Swelling deformation and pressure are further significant future associated to hydration-mechanical properties, and found that two testing series are conducted out using unsaturated odometer apparatus explained in Section 2.2 Testing apparatus. Then, two difference vertical stresses were loaded to unsaturated specimens in which were 186 $\mathrm{kPa}$ and $1500 \mathrm{kPa}$, respectively. When two external loading was applied, specimens had slight vertical displacement, because of compaction stress over $5 \mathrm{MPa}$ as pre-compression stress.

A specimen with vertical stress of $186 \mathrm{kPa}$ created sufficient swelling deformation at beginning of absorption as shown in Fig. 7 that was subsequently stable over thirty days. Deformation was calculated to changing of dry density. Dry density obtained from swelling test was $1.361 \mathrm{Mg} / \mathrm{m}^{3}$ when end of test, which decreased to $66 \%$ for initial dry density (i.e. $1.650 \mathrm{Mg} / \mathrm{m}^{3}$ ). A point of inflection to swelling deformation was found that it was eight days in testing period, and dry density of 1.420 $\mathrm{Mg} / \mathrm{m}^{3}$ was indicated. Other hand, decreasing of dry density at vertical stress of $1500 \mathrm{kPa}$ was observed, as well as case of vertical stress of $186 \mathrm{kPa}$ that swelling 


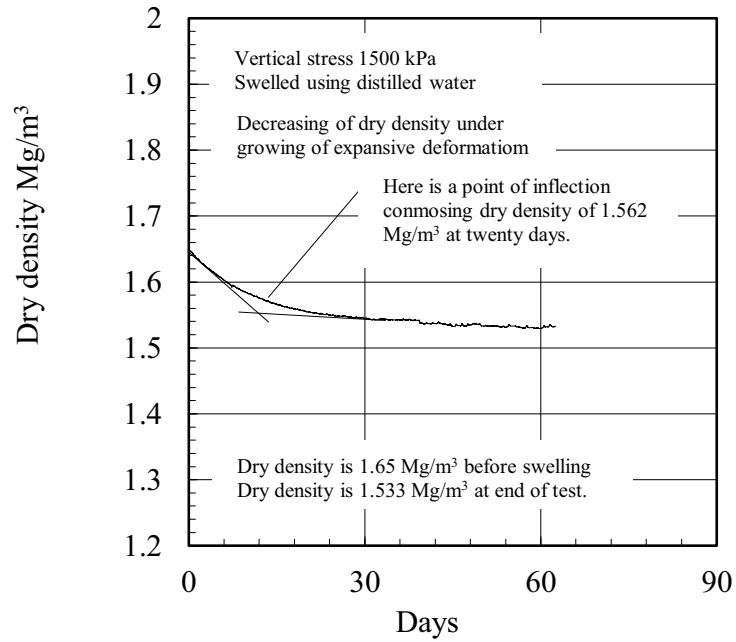

Figure 8. Reduction of dry density in swelling deformation test at vertical stress of $1500 \mathrm{kPa}$.

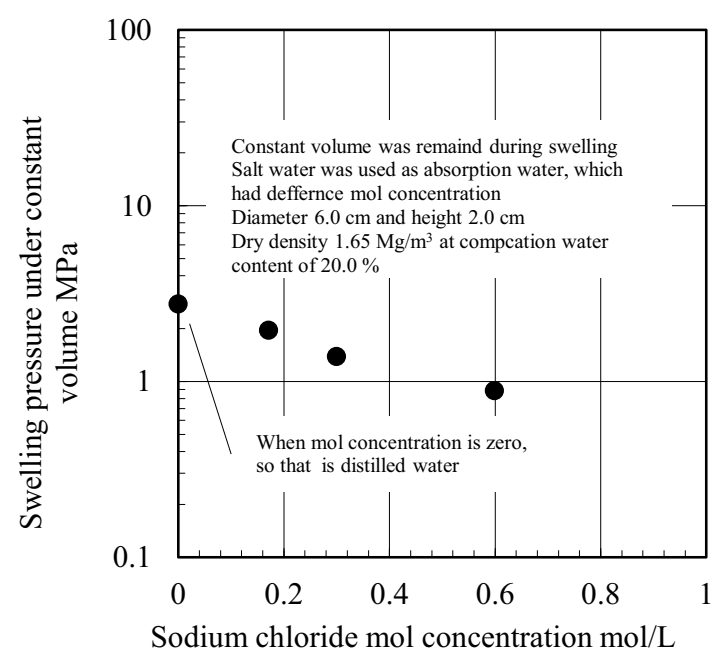

Figure 9. Swelling pressure under constant volume with sodium chloride mol concentration.

deformation occurred at beginning of absorption as shown in Fig. 8. Dry density was $1.533 \mathrm{Mg} / \mathrm{m}^{3}$ at end of test, which was equal to $93 \%$ for initial dry density (i.e. 1.650 $\left.\mathrm{Mg} / \mathrm{m}^{3}\right)$. Degree of dry density reduction was just not comparable comparing $186 \mathrm{kPa}$ and $1500 \mathrm{kPa}$ in vertical stress. A point of inflection to swelling deformation was twenty days, which was longer than that of vertical stress of $186 \mathrm{kPa}$. It was therefore obviously that influence of vertical stress on swelling deformation was significant effort, and changing of deformation with absorption time, however, be not similar to each together.

In addition. swelling pressure, as well as, is important properties in hydration-mechanical properties, this study performed swelling pressure test associated to maintain initial volume of specimen during absorption using distilled water and salinity chloride. Salinity chloride solutions had various concentrations. It has been mentioned commonly that expansive soil materials with rich montmorillonite fractions is influenced by chloride ion on expansive behaviour. Increasing of sodium chloride create to variate swelling pressure, and swelling pressure reduction could recognize extremely as

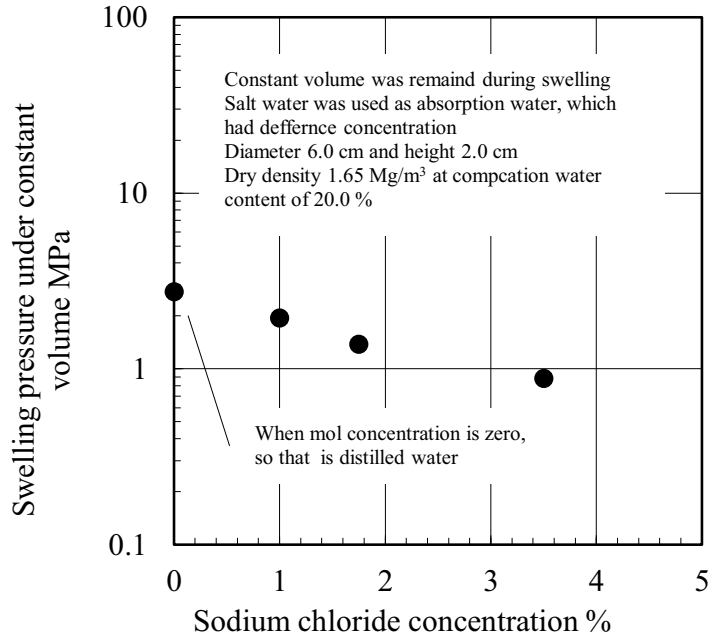

Figure 10. Swelling pressure under constant volume with sodium chloride concentration.

shown in Figs. 9 and 10, which sodium chloride mol concentration were plotted in Fig. 9, and sodium chloride concentration was described in Fig. 10, respectively. A tendency was found that a linear relationship was satisfied well. Swelling pressure due to distilled water compared to swelling pressure using salinity chloride that measured swelling pressure was further larger than those of specimen subject to salinity chloride solution. The results are approximately stable to some experimental works on swelling properties associated to salinity components.

\section{Hydraulic conductivity of saturated calcium bentonite}

It has been predicted that erosion for canister made of stiffness stainless material due to chemical reaction at steel metal and chloride solutions interface, and subsequently corrosion materials diffuse toward the barrier structure. To understand hydraulic conductivity for saturated calcium bentonite is indispensability using continued models to confirm diffusion of process, diffusion period and spread layer thickness. This study measured the coefficient of permeability following a Darcy's law, and saturated calcium bentonite specimens were prepared with different dry densities. Required a range for dry densities was from $1.045 \mathrm{Mg} / \mathrm{m}^{3}$ to 1.650 $\mathrm{Mg} / \mathrm{m}^{3}$. Permeated solution liquid was distilled water and salinity chloride, which the salinity was $3.5 \%$. Permeation was induced by hydraulic gradient, solutions passed through saturated specimens under controlled hydraulic gradient. Outflow solutions were collected into glass burette. Salinity concentrations of permeable liquid in glass burette was determined using conventional salinity meter, and compared to initial solutions. The coefficient of permeability for saturated calcium bentonite was clearly influenced as shown in Fig. 11 that conductivity had a reduction according to increment of dry density, and chloride salinity ion solution effected to develop permeability. To include chloride salinity in soil moisture, developed to be approximately ten times for coefficient of 


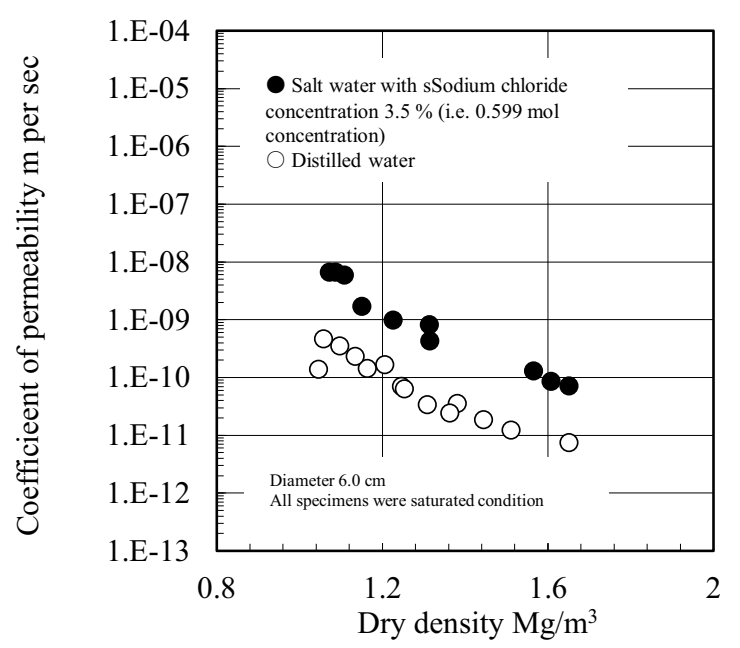

Figure 11. Influence of dry density on hydraulic conductivity.

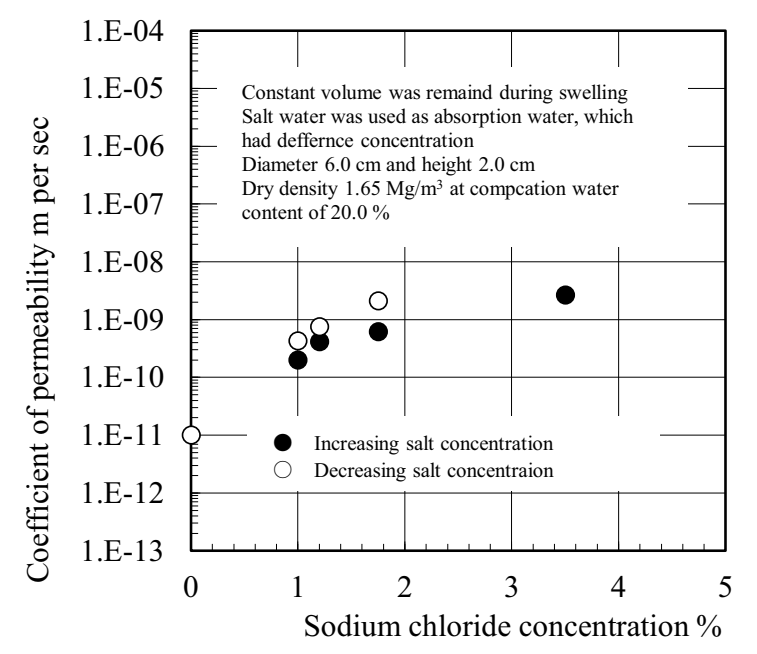

Figure 12. Changing of hydraulic conductivity due to increment and decrement for sodium chloride concentration.

permeability comparison with saturated calcium bentonite subjected to distilled water.

Increment and decrement repletely in salinity was applied to a saturated calcium bentonite, hydraulic conductivity was measured in order to consider the influence of salinity components. Permeability test was conducted out using a sodium chloride concentration of $1.0 \%$, subsequently the concentration increased up to $3.5 \%$ through each step, and permeability was evaluated at each concentration. It was found that development of conductivity was sufficiently indicated as shown in Fig. 12. Continuously, salinity of solution though saturated calcium bentonite was reduced, and compared to previous coefficient of permeability. Evaluated coefficient of permeability clearly decreased with decreasing of salinity. It was no variation to the coefficient during increment of salinity. Further reduction of conductivity was observed when the distilled water was flowed into saturated specimen instead of salinity chloride solution. It was verified that salinity chloride in soil moisture extremely could affected to hydraulic conductivity.

\section{Conclusions}

This study presents the results of HMC experimental test and discussions of chemical effort in $\mathrm{Ca}$ - bentonite. SWCC test, swelling pressure test and unconfined compression test as hydro-mechanical-chemical (HMC) test were applied to Ca-bentonite-sand mixture. The summaries were evidenced as following: Unconfined compressive strengths for unsaturated Calcium bentonite is of suction effort and modulus rigidly. It is possible to verify changing of strength on a straight-line associate to suction in logarithmic scale. Swelling pressure at constant volume was measured when sodium chloride mol concentration was less $0.6 \mathrm{~mol} / \mathrm{L}$, and it indicated the decreasing with concentration. Then, the relationship was not just hyperbolic function and approximately linear function. Hydraulic conductivity determined using chloride salinity solution was further larger than that of distilled water that was common interpretation in previous works. Well, a slightly heresies to hydraulic conductivity was observed due to changing chloride salinity repletely.

\section{References}

1. M.V. Villar. (2005). MX-80 bentonite: Thermohydro-mechanical characterisation performed at CIEMAT in the context of the prototype project.

2. N. Mokni., E. Romero. \& S. Olivella. (2014). Chemohydro-mechanical behaviour of compacted Boom Clay: joint effects of osmotic and matric suctions, Géotechnique, 64, 9, 681-693.

3. L. Xiaodonga., R. Prikry. \& R. Pusch. (2011). THMC-testing of three expandable clays of potential use in HLW repositories, Applied Clay Science, 52, 4, 419-427.

4. L.O. Lee., J. G. Lim., Mo. Kang. \& S. Kwon. (2012). Swelling pressures of compacted Ca-bentonite, Engineering Geology, 129-130, 20-26.

5. Ph. Geneste., M. Raynal., R. Atabek., M. Dardaine. \& J. Oliver. (1990). Characterization of a french clay barrier and outline of the experimental programme, Engineering Geology, 28, 3-4, 443-454. 